which found no effect on athletic performance studied untrained men and used androstenolone ${ }^{10}$ or stanozolol. ${ }^{14}$

To avoid the pitfalls suggested by Ariel and Saville's ${ }^{15}$ finding that placebo produced significant improvements in performance, each of our athletes acted as his own control.

We found more side effects than others have reported; in particular acne has never been reported under these conditions though it is a recognized complication of androgen therapy, nor have we seen reports of "urethritis." The occasional high SGPT levels were unassociated with symptoms or signs and might have reflected enzyme induction rather than liver damage. ${ }^{18}$

Anecdotal Lore.-We have heard of doses of up to $300 \mathrm{mg} /$ day being taken for months or even years, but the consensus of opinion is that huge doses are no more useful than the moderate doses we used. As might be expected from nitrogen balance studies $^{17}$ the effect of anabolic steroids seems to wane after about six weeks in spite of continuing treatment. The gains are usually maintained for some weeks after stopping the drug, but then follows a period of relative weakness which may last for several weeks. On steroids athletes generally become less susceptible to fatigue, which allows longer, more frequent, and harder training sessions. Injuries to muscles, tendons, and ligaments occur less often in weight training, and when they do occur they heal more quickly than usual. These two features might provide a clue to the mechanism of these drugs. Among side effects of steroids we have heard of jaundice, hypertension, urethritis, gastrointestinal haemorrhage, increased and decreased libido, and oligospermia. Inevitably many of the correlations implied by these anecdotes are incidental. Acne and headache are so widely mentioned as to confirm our own findings.

Such anecdotal data are of little strict value, but we cannot mount the very large trial needed to test them objectively. Highly trained dedicated athletes are rare and few are interested in co-operating in such studies; this is especially true in Britain where top-class athletic training is unrewarding and often lonely, requiring of its practitioners a large degree of obsession.

\section{ETHICAL CONSIDERATIONS}

The taking of anabolic steroids by athletes, and thus our trial, may be criticized on the grounds that (a) these drugs give a competitor an unfair advantage over opponents not taking them; and $(b)$ it is wrong to give a drug to a healthy person. On the other hand, anabolic steroids are reputed to be taken by almost all international heavy athletes, and if this is so then not to take them is to submit to an unfair disadvantage. We also felt justified in proceeding with our trial because the athletes would have obtained and taken the drugs even if we had not condoned it (some already had), and in that case it were better they did so under medical supervision.

Nevertheless, neither of these arguments detracts from the force of the ethical objections posed. It is wrong that athletes should be subjected to short-term competitive pressures which might damage their health in the long term, and we would support any measure to prevent this abuse of anabolic steroids. Enforcement of such a ban would mean, however, that contestants should have regular blood or urine tests for at least two months before a competition, and we doubt if this could be carried out internationally. Anabolic steroids are now rarely prescribed by doctors and there is a flourishing black market in them. Presumably they reach competitors in this country from abroad or via unscrupulous individuals in the chain of pharmaceutical distribution.

We gratefully acknowledge the facilities provided by Mr. R. St G. T. Harper and Mr. R. Walker at the McDougall Sports Centre, Manchester University, and the statistical work of Mrs. S. Standen of CIBA Laboratories.

\section{References}

${ }^{1}$ Desaulles, P. A., et al., Schweizerische medizinische Wochenschrift, 1959

89, 1313 .
2 MIMS Annual Compendium 1972, pp. 74 and 257. London, Haymarket Publications, 1972

3 Wade, N., Science, 1972, 176, 1399.

4 British Medical fournal, 1967, 4, 310.

Wynn, V., Landon, J., and Kaweran, E., Lancet, 1961, 1, 69.

Liddle, G. W., and Burke, H. A., Helvetica Medica Acta, 1960, 27, 504. James, v. H. T., Landon, J., and Wynn, V., fournal of Endocrinology,

8 Wynn, B., in Modern Trends in Endocrinology, 3, ed. H. Gardiner-Hill, London, Butterworths, 1967.

${ }^{9}$ Boris, A., Stevenson R. H., and Trmal, T., Steroids, 1971, 15, 61.

10 Fowler, W. M., Gardner, G. W., and Egstrom, G. H., fournal of Applied Physiology, 1965, 20, 1038.

11 Johnson, L. C., and O'Shea, J. P., Science, 1969, 164, 957.

12 O'Shea, J. P., Nutrition Report International, 1971, 4, 363.

13 O'Shea, J. P., Nutrition Report International, 1971, 4, 363. 43.

13 Johnson, L. C., et al., Medicine and Science in Sports, 1972, 4, 43. Medicine and Physical Fitness, 1971, 11, 98.

15 Ariel, G., and Saville, W., Medicine and Science in Sports, 1972, 4, 124. ${ }_{16}$ British National Formulary, 1974-76, p. 125. London, British Medical Association, 1974.

17 Imhof, P., Médecine et Hygiène, Genève, 1968, 841, 1137.

18 Baron, D. N., personal communication, 1972.

\title{
Variations in Leucocyte Count during Menstrual Cycle
}

\author{
BARBARA J. BAIN， J. M. ENGLAND
}

British Medical fournal, 1975, 2, 473-475

\section{Summary}

The neutrophil counts of seven women, three taking oral contraceptives and four not taking them, showed cyclical variations during the menstrual cycle, most consistently a fall in the neutrophil count at menstruation. The

neutrophil count in women not taking oral contraceptives rose to a peak twice during each cycle.

One woman not taking oral contraceptives was studied in detail over eight consecutive menstrual cycles. She showed two neutrophil peaks per cycle and a similar variation in the monocyte count. The eosinophil count showed a reciprocal relation with the neutrophil count and the basophil count fell in mid-cycle. The changes in her neutrophil count seemed to follow changes in oestrogen level with a delay of one to two days. Oestrogen probably promotes release of neutrophils from the bone marrow rather than from the marginated pool.

\section{Introduction}

Women have significantly higher neutrophil counts than men, 
which suggests that physiological levels of oestrogen or progesterone influence the leucocyte count. Thus changes in the count might occur when the hormonal balance changes during the menstrual cycle.

We therefore reinvestigated the variation in the leucocyte count during the menstrual cycle and tried to correlate our findings with changes in hormone levels. We studied a few women in great detail and standardized the conditions as precisely as possible to avoid the effects of exercise and diurnal variation.

\section{Subjects and Methods}

Four normal women aged 21 to 35 (cases 1-4) were studied, one for nine cycles, eight of them consecutive ( 11 menstrual periods) and the others for five cycles (nine menstrual periods). Three women aged 21 to 30 who were taking oral contraceptives were also studied for four menstrual cycles (seven menstrual periods). Their oral contraceptives contained ethinyloestradiol $50 \mathrm{mg}$ and either norethisterone acetate $1 \mathrm{mg}$, norgestrel $0.5 \mathrm{mg}$, or lynoestrenol $2.5 \mathrm{mg}$. Venous blood samples anticoagulated with $\mathrm{K}_{2}$ EDTA were obtained between 8.00 and 10.00 a.m. (but within a constant half-hour period for each individual). Subjects were studied consistently either before or after breakfast and after 30 minutes' rest in the sitting position.

The total white cell count was determined using a Coulter counter, Model S, standardized with Coulter 4C cell control. Differential counts were performed on 500 cells by one observer counting in longitudinal strips on Romanowsky-stained blood films. To assess the precision of the counting triplicate differential counts were performed on 19 samples, and the overall standard deviations were as follows: neutrophils $2 \cdot 0 \%$, lymphocytes $2 \cdot 3 \%$, monocytes $1.5 \%$, eosinophils $0.4 \%$, and basophils $0.2 \%$. Platelet counts were performed using a Coulter counter, Model D. ${ }^{2}$

The days of each cycle were numbered from 0 , and three-day moving "averages" were calculated for the leucocyte and platelet counts and the haemoglobin concentration. Averages were taken of each day's count, the previous count, and the succeeding count and related to the mean number for those three days. For the leucocyte counts the geometric means were used as the "average" values, ${ }^{1}$ and for the platelet count and haemoglobin concentration arithmetic means were calculated.

In the woman (case 1) who was studied for eight consecutive menstrual cycles all the results were pooled. The days of each cycle were numbered from zero as before and the day numbers were then multiplied by a correction factor so that each cycle became 28 days long. The results of all eight cycles were then amalgamated in the order of ascending day numbers, and 24-point moving averages, corresponding to about three days, were calculated as above.

Serum progesterone, oestradiol, and cortisol levels were also measured in case 1 using radioimmunoassay with antisera to progesterone-11 $\alpha$-hemisuccinylbovine serum albumin and plasma extracted with Fischer petroleum ether; antisera to oestradiol-6-(0-carboxymethyl)-oximino-bovine serum albumin and plasma extracted with purified redistilled ether; and antisera to cortisol-3-(0-carboxymethyl)-oximino-bovine serum albumin and ethanol-treated plasma.

\section{Results}

VARIATIONS IN LEUCOCYTE COUNT

All the women showed cyclical variations in the total leucocyte count during the menstrual cycle, due mainly to changes in the neutrophil count. The most consistent feature, seen in all women, was a fall in the neutrophil count during menstruation. The neutrophil counts of the four women not taking oral contraceptives increased after menstruation and usually showed two peaks before the next menstrual period (fig. 1). The depth of the fall between the two peaks varied. The three women on oral contraceptives showed a less consistent pattern, a definite menstrual fall being observed in only five of the seven menstrual periods studied.

\section{DETAILED STUDY}

In case 1 the cyclical variation in the neutrophil count occurred over eight consecutive cycles, and the monocyte count showed a similar variation (fig. 2). At each menstrual period the neutrophil count fell sharply from a peak one to five days before the onset of menstruation

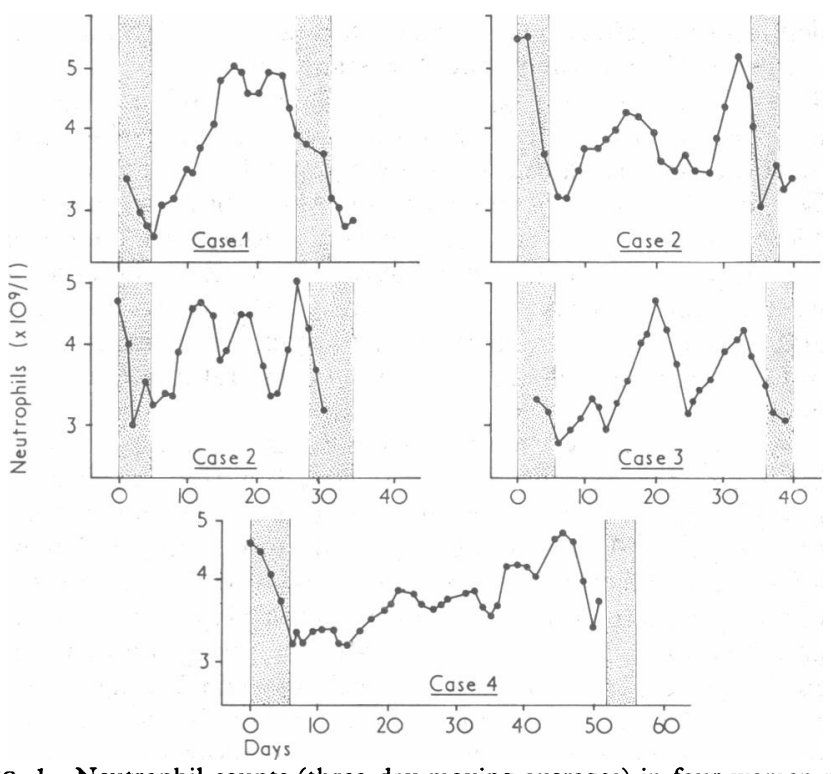

FIG. $1-$ Neutrophil counts (three-day moving averages) in four wom
taking oral contraceptives. Shaded areas represent menstrual periods.

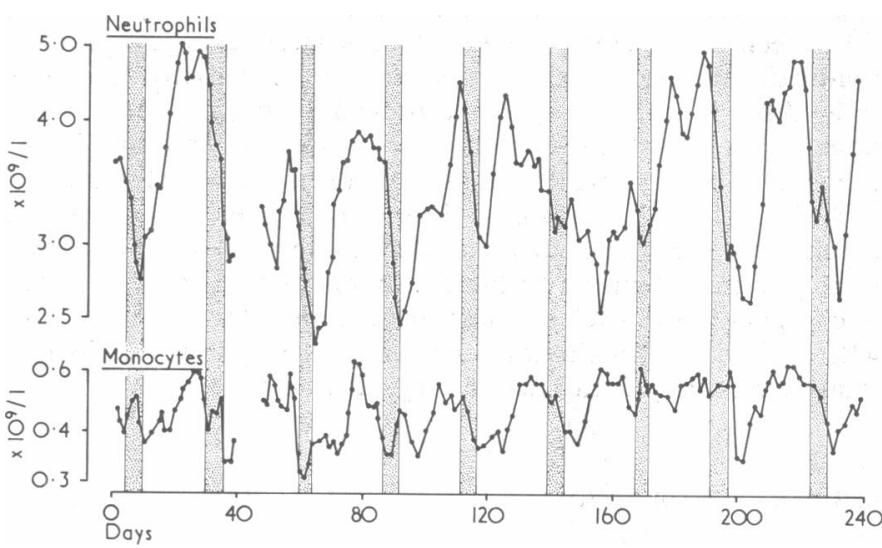

FIG. 2-Neutrophil and monocyte counts over 240 days in case 1 (three-day moving averages). Shaded areas represent menstrual periods.

to a nadir which occurred any time from one day before to 10 days after menstruation stopped. From the nadir there was a steady rise, which in at least seven cycles was clearly established before the time of ovulation as predicted from the basal temperature chart. ${ }^{3}$ In several cycles the count fell again and then rose to a second peak.

When the results for the eight consecutive cycles were pooled the variations in total leucocyte, neutrophil, and monocyte counts were still evident (fig. 3). No substantial variations were evident in the lymphocyte count. The eosinophil count showed a cyclical variation which was inversely related to those of the neutrophil and monocyte counts; it rose during menstruation and fell throughout the rest of the cycle. The basophil count was lowest at the onset of menstruation, rising to a peak at the 10th day and falling to a trough around day 15 . The platelet count showed only minor variations, being highest during and after menstruation and lowest in the second and third weeks. The haemoglobin concentration showed only trivial fluctuations.

Marginating Leucocytes.-To determine whether the variations in neutrophil count during the menstrual cycle were due to redistribution between the marginated and circulating granulocyte pools we studied the effects of exercise at various times during the cycle (see table). Exercise had similar effects at different phases of the cycle, which suggested that shifts to and from the marginated pool were not responsible for the menstrual variations, at least in this subject.

Oestradiol and Progesterone Levels.-We measured oestradiol, progesterone, and cortisol during one menstrual cycle to see whether these could be related to variations in the leucocyte count (fig. 4). The usual changes in hormone levels were observed, with two peaks in the oestradiol curve on days 12 and 19 and one peak in the progesterone curve on day 19. The cortisol levels were higher during the first menstrual period than during the second. The neutrophil count 


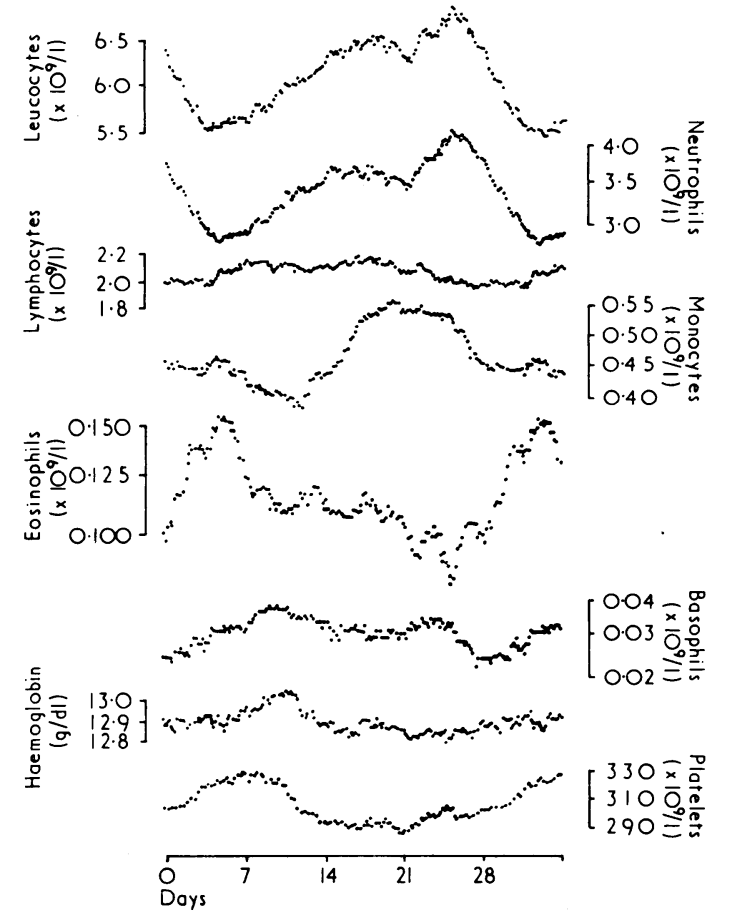

FIG. 3-Leucocyte counts, haemoglobin concentrations, and platelet counts in case 1 . Results for eight menstrual cycles were standardized to 28-day menstrual cycle and pooled. Day 0 represents first day of menstruation.

Case 1. Neutrophil Count $\left(\times 10^{9} / l\right)$ Before and After Exercise (62 Watts for 360 seconds) on Bicycle Ergometer

\begin{tabular}{|c|c|c|c|c|c|c|}
\hline & Day: & 48 & 55 & 61 & 64 & 82 \\
\hline $\begin{array}{l}\text { Before exercise } \\
\text { After exercise } \\
\% \text { Increase .. }\end{array}$ & $\begin{array}{l}\ldots \\
\cdots\end{array}$ & $\begin{array}{c}3 \cdot 819 \\
5 \cdot 134 \\
34\end{array}$ & $\begin{array}{c}3.969 \\
5.478 \\
38\end{array}$ & $\begin{array}{c}3.080 \\
4.464 \\
45\end{array}$ & $\begin{array}{c}2 \cdot 331 \\
3 \cdot 245 \\
39\end{array}$ & $\begin{array}{l}3.855 \\
4.635 \\
20\end{array}$ \\
\hline
\end{tabular}

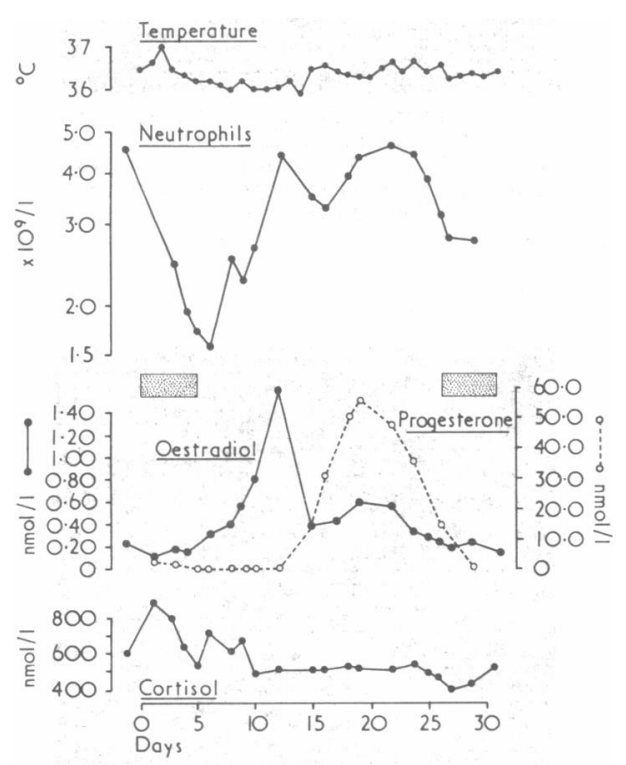

FIG. 4-Basal body temperature, neutrophil counts on individual days, and plasma oestradiol, progesterone, and cortisol, in case 1 during one menstrual cycle. Shaded areas represent menstrual periods.

Conversion: SI to traditional units-Oestradiol: $1 \mathrm{nmol} / \approx 272 \mathrm{pg} / \mathrm{ml}$. Progesterone: $1 \mathrm{nmol} / 1 \approx 0.314 \mathrm{ng} / \mathrm{ml}$. Cortisol: $1 \mathrm{nmol} / 1 \approx 0.0362 \mu \mathrm{g} / 100 \mathrm{ml}$. started to rise on day eight after the oestrogen levels had been increasing for two days, and the two peaks in the neutrophil count corresponded with the hormonal peaks on days 12 and 19 .

\section{Discussion}

The most noticeable feature in the cyclical variation of the neutrophil count was the fall during menstruation which has been described previously. ${ }^{4}{ }^{5}$ Morley has also suggested the existence of a neutrophil cycle related to menstruation, ${ }^{6}$ though his findings have been reappraised. ${ }^{7} 8$

The fall we saw in the neutrophil count suggested that decreasing oestrogen and progesterone levels might have been responsible for it, and we were able to confirm this relation in one woman. The changes in the neutrophil count followed the changes in the oestradiol level so closely that a cause and effect relationship was suggested. The two peaks in the neutrophil curve were similar, though the second oestradiol peak was much smaller than the first. The second oestradiol peak may therefore be sufficient to produce a maximum neutrophil response, or progesterone may also exert an influence. With such a brief delay period the oestrogen probably acts by releasing mature neutrophils from the marrow granulocyte reserve. Mobilization of marginated neutrophils does not appear to be a significant factor, though we studied this in only one woman.

High doses of oestrogen increase the neutrophil count in dogs ${ }^{9} 10$ and mice. ${ }^{11}$ Furthermore, in women treated with follicle-stimulating hormone and chorionic gonadotrophin there is a correlation between the oestrogen levels and the neutrophil count, ${ }^{12}$ and oestrogen seems to enhance neutrophil proliferation in vitro. ${ }^{13}$

The monocyte and neutrophil counts varied in a similar manner throughout the menstrual cycle, which suggested that they have a similar regulatory mechanism. There was a reciprocal relationship between the neutrophil count and the eosinophil count, which has not been described. The eosinophil count did not seem to correlate with the cortisol levels, which suggested that variations were due to some other mechanism, either a direct hormonal effect on eosinophil kinetics or an effect secondary to altered neutrophil release. The basophil count fell in mid-cycle. A similar dip has been described, coincident with ovulation, by Thonnard-Neumann ${ }^{14}$ and Mettler and Shirwani. ${ }^{15}$

We thank our colleagues who volunteered for this study and Professor P. L. Mollison, Professor V. H. T. James, and Dr. S. N. Wickramasinghe for their helpful suggestions. Serum progesterone, oestradiol, and cortisol leyels were kindly measured by Dr. D. Fahmy at the Tenovus Institute for Cancer Research. Miss M. C. Down kindly prepared the illustrations.

\section{References}

1 Bain, B. J., and England, J. M., British Medical fournal, 1975, 1, 306.
2 Bull, B. S., Schneiderman, M. A., and Brecher, G., American fournal of Clinical Pathology, 1965, 44, 678 .

3 Balin, H., and Glasser, S., Reproductive Biology. Amsterdam, Excerpta Medica, 1972.

4 MacKinnon, I. L., Fournal of Obstetrics and Gynaecology of the British Empire, 1953, 60, 721 .

5 Heine, K., Heine, H., and Schmidt, H., Acta Biologica Medica Germanica, $1959,4,358$

6 Morley, A., Lancet, 1966, 2, 1220.

7 Morley, A., Blood, 1973, 41, 329.

8 Maughan, W. Z., et al., Blood, 1973, 41, 85.

9 Crafts, R. C., Endocrinology, 1941, 29, 606.

10 Tyslowitz, R., and Dingemanse, E., Endocrinology, 1941, 29, 817.

11 Fox, L. E., Fournal of Pharmaceutical Sciences, 1961, 50, 436.

12 Cruickshank, J. M., et al., Fournal of Obstetrics and Gynaecology of the British Commonwealth, $1972,79,450$.

British Commonwealth, 1972, 79, 450 .
13 Reisner, E. H., Blood, 1966, 27, 460 .

14 Reisner, E. H., Blood, 1966, 27, 460.

15 Mettler, L., and Shirwani, D., American fournal of Obstetrics and Gynacology, 1974, 119, 1038. 